\title{
Management of tracheomediastinal fistulas using self-expanding metallic stents
}

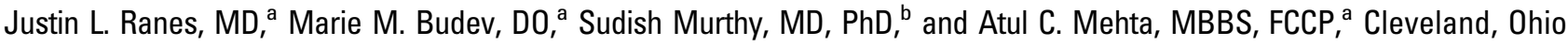

\section{Clinical Summary}

A 69-year-old woman with a history of cancer of the left breast requiring radiation treatment, non-small cell lung cancer requiring left upper lobectomy, and small cell lung cancer requiring right lower lobectomy and chemotherapy $(21,14$, and 7 years ago, respectively) had subcarinal lymphadenopathy. This area demonstrated avid uptake on positron emission tomographic scanning. A left thoracotomy and excisinal biopsy were performed. During the procedure a communication between the left main stem bronchus and mediastinum was noted. After an unsuccessful open repair with an intercostal muscle flap, she was transferred to our institution with worsening subcutaneous emphysema.

Examination with a flexible bronchoscope, performed via an endotracheal tube, revealed a transmediastinal fistula (TMF) involving both main-stem bronchi (Figure 1). A large amount of mucopurulent material was aspirated from the TMF, the culture of which grew Pseudomonas aeruginosa.

No additional open surgical intervention was undertaken. A dynamic Y-stent (Rüsch) was not favored because of the complicated depolyment. Placement of self-expanding metallinc stents (SEMS) across both mainstem bronchi was decided upon.

Uncovered $14 \times 40$ and $12 \times 20 \mathrm{~mm}$ Ultraflex stents (Boston Scientific, Natick, Mass) were placed in the left and right main-stem bronchi, respectively. The patient tolerated the procedure well, was extubated the next day, the subcutaneous emphysema rapidly resolved, and the patient was discharged on day 6 .

Examination with a flexible bronchoscope at the fifth and tenth weeks revealed dramatic healing of the fistula. At the thirteenth week the defect had completely healed, so the right main-stem bronchus stent was removed (Figure 2). The stent in the left main bronchus was left in place. Subsequent bronchoscopies confirmed complete closure of the TMF. Eighteen months postoperatively the patient remains free of symptoms,

From the Department of Pulmonary, Allergy, and Critical Care Medicine and the Department of Thoracic and Cardiovascular Surgery ${ }^{\mathrm{b}}$, the Cleveland Clinic Foundation, Cleveland, Ohio.

Received for publication Sept 22, 2005; accepted for publication Oct 7, 2005.

Address for reprints: Sudish Murthy, MD, PhD, Department of Thoracic and Cardiovascular Surgery, Cleveland Clinic Foundation, 9500 Euclid Ave, Desk A90, Cleveland, OH 44195 (E-mail: ranesj@ccf.org).

J Thorac Cardiovasc Surg 2006;131:748-9

$0022-5223 / \$ 32.00$

Copyright $\odot 2006$ by The American Association for Thoracic Surgery doi:10.1016/j.jtcvs.2005.10.024 maintaining total patency of both main bronchi without any evidence of granulation tissue.

\section{Discussion}

Many factors contributed to fistula formation in the patient. It is likely that the biopsy attempt injured and devasularized the carina. Also, prior radiation has distorted the tracheal and bronchial architecture, weakening their integrity. Finally, resulting mediastinitis promoted additional tissue distruction.

SEMS have been increasingly used in airway obstruction caused by malignant processes and the covered SEMS have been used to seal tracheo-esophageal fistulas. ${ }^{1}$ Their role in the treatment of benign conditions has been controversial, though their use has been documented in relapsing polychrondritis ${ }^{2,3}$ and in the treatment of anastamotic complications following lung transplantation. $^{3,4}$

We felt that SEMS were the appropriate choice both because of ease of insertion and that no rigid instrumentation was required. Further, we felt that the "drawback" associated with SEMS, that they promote the formation of granulation tissue, ${ }^{5}$ could be used to our advantage in this case. Selection of an uncovered stent allowed drainage of the mediastinal infection and obviated the risk of bacterial colonization of the stent.

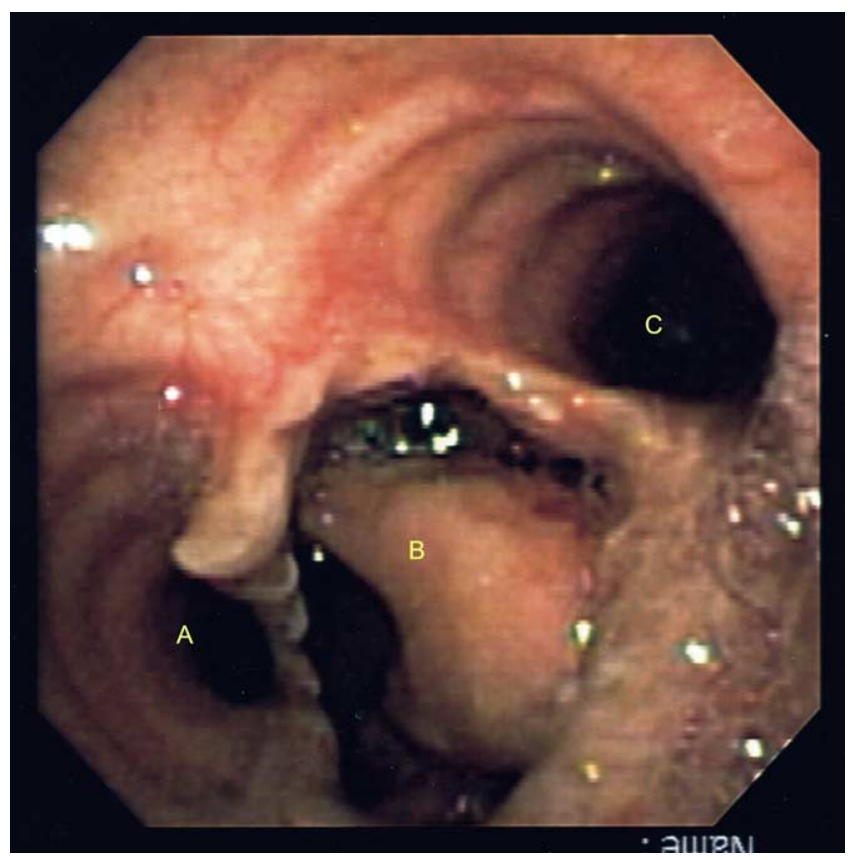

Figure 1. Transmediastinal fistula involving both main-stem bronchi. A: Left main-stem bronchus. B: Tracheomediastinal fistula. C: Right main-stem bronchus. 


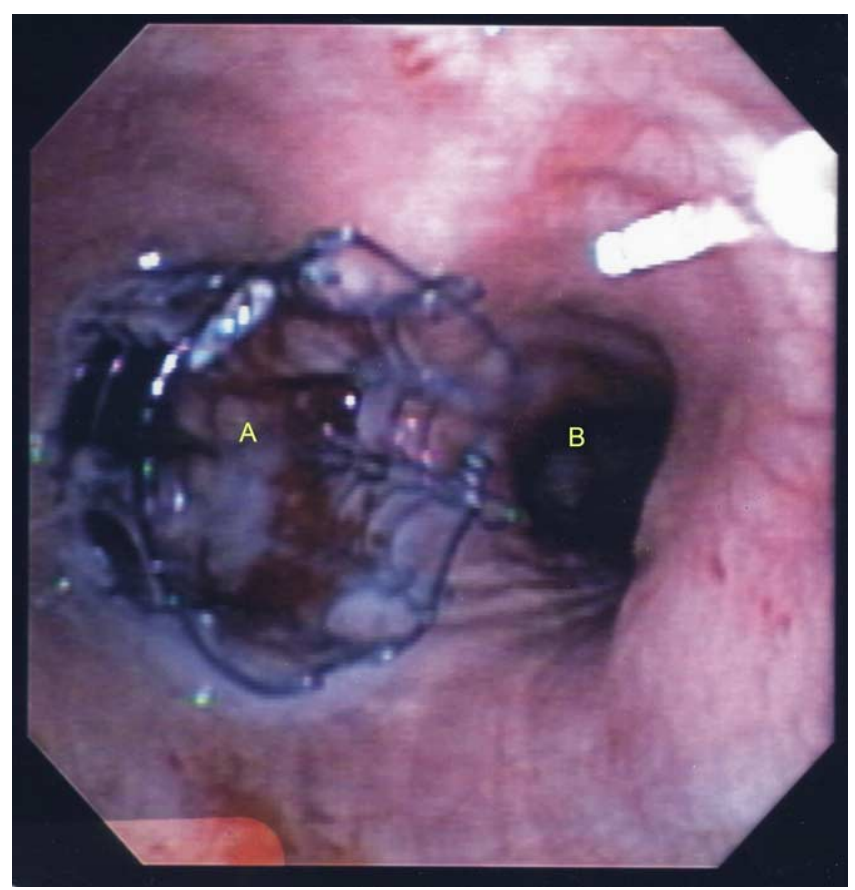

Figure 2. A: Left main-stem bronchus with stent in place. B: Right main-stem bronchus after stent removal.

\section{Conclusion}

SEMS, by promoting formation of granulation tissue, are efficacious in the treatment of complex airways fistulas. This case demonstrates a quick response with notable improvement in 5 weeks and near complete fistula closure by 3 months.

\section{References}

1. Mehta AC, Dasgupta A. Airway stents. Clin Chest Med. 1999;20: 139-51.

2. Sarodia BD, Dasgupta A, Mehta AC. Management of airway manifestations of relapsing polychondritis: case reports and review of literature. Chest. 1999;116:1669-75.

3. Saad CP, Murthy S, Krizmanich G, Mehta AC. Self-expandable metallic airway stents and flexible bronchoscopy: long-term outcome analysis. Chest. 2003;124:1993-9.

4. Mughal M, Gildea TR, Murthy S, et al. Short-term deployment of self-expanding metallic stents facilitates healing of bronchial dehiscence. Am J Respir Crit Care Med. 2005;172:786-71.

5. Wood DE, Liu YH, Vallieres E, Karmy-Jones R, Mulligan MS. Airway stenting for malignant and benign tracheobronchial stenosis. Ann Thorac Surg. 2003;76:167-72. 